\title{
Assessment of the Design Provisions for Steel Concentric X Bracing Frames with Reference to Italian and European Codes
}

\author{
Beatrice Faggiano ${ }^{*}$, Luigi Fiorino, Antonio Formisano, Vincenzo Macillo, Carmine Castaldo \\ and Federico M. Mazzolani
}

Department of Structures for Engineering and Architecture, University of Naples “Federico II”, Naples, Italy

\begin{abstract}
In the field of construction in seismic areas, the current Italian technical code for constructions NTC2008 is substantially based on the design criteria of Eurocode 8 (EC8), although with some differences. Focusing on steel structures with X Concentric Braces (CB), which is one of the most common seismic resistant structural typology in steel buildings, the paper illustrates a critical review of design methodologies specified in NTC2008, with the intent of providing simplified and more efficient design criteria and procedures able to ensure adequate safety levels under seismic actions, according to the modern design approach. The study is divided in two parts. The first part consists in the design according to the standard rules of typical steel $\mathrm{X}$ braced structures by linear analysis, both static and dynamic. The aim is identifying any possible weakness in the current design criteria, with particular reference to both the applicability of the proposed procedures and the actual possibility to size the bracing cross-sections and the connected structural members, like beams and columns. The second part consists in the assessment of the seismic response of structures examined. To this purpose, non-linear static analyses are performed in order to evaluate the most relevant behavioural issues, like the behaviour factor, the failure modes and the effectiveness of the capacity design criteria. Based on the results obtained, a proposal for the enhancement of design criteria is presented.
\end{abstract}

Keywords: Behaviour factor, concentrically braced frames, non linear static analyses, overstrength factor, seismic design criteria, seismic resistant steel structures.

\section{THE RESEARCH CONTEXT}

In recent years a twofold occurrence has motivated the review for maintenance of technical codes for design and construction in seismic areas: on one hand the huge amount of research results and advances in the state of knowledge in the field of seismic engineering, on the other hand the frequent recurrence all over the world of seismic events of high intensity and serious consequences. Unfortunately this is the actual context also for Italy, which has been recently theatre of severe earthquakes striking both historical centres and modern buildings, even devoted to productive activities. With particular focus on steel structures, a crucial moment for the development of seismic design codes for steel constructions has been the draft of OPCM 3274 and 3431 [1] since 2003, which introduced an extensive chapter, in line with EC8: Design of structures for earthquake resistance Part 1: General rules, seismic actions and rules for buildings [2], with the addition of some noticeable changes on the design of steel structures with respect to the European standard, integrating the evidences of extensive studies on the seismic behaviour. However these amendments were not included in the current technical standards, in a view of guarding the symmetry with EC8 [3]. What is more, the current Italian NTC2008 [4] has several cuts with respect to EC8, which were partially recovered in the explicative Italian Ministerial Circular [5].

*Address correspondence to this author at the Department of Structures for Engineering and Architecture, University of Naples "Federico II", Naples, Italy; Tel: (+39) 081.7682447; E-mail: faggiano@unina.it
Therefore the need to fill this gap, incorporating and merging all the most updated achievements of research related to the design of seismic resistant systems motivated the Italian project RELUIS-DPC (2010-2013), specifically focused on these issues. In particular, the task of the research unit UNINA-ING was the optimization of design criteria for seismic resistant steel braced structures. First results of this research activity were provided in De Lucia et al. [6] and Macillo et al. [7, 8], with respective reference to X-braced structures and chevron braced structures, the latter being described in Castaldo et al. [9]. The research is ongoing in the framework of the new edition for the year 2014 of the Italian project RELUIS-DPC.

\section{NTC2008 DESIGN CRITERIA FOR CBF-X STRUC- TURES}

In Concentrically Braced Frames (CBF), the resistance against the seismic actions is provided by the contribution of both tensile and compression braces. The ideal design ultimate condition of a dissipative braced system is the simultaneous buckling of compression bracings and yielding of tensile ones, the braces being the dissipative elements $[10,11]$. According to the commonly accepted resistance hierarchy criterion, the other structural elements, such as columns, beams and connections, have to remain in elastic range and, therefore, they should be designed to have an adequate overstrength as respect to braces. Hereafter the Ultimate Limit State (ULS) design rules for seismic resistant systems with $\mathrm{X}$ braces (CBF-X) are summarised. 
Firstly, as for all the seismic resistant systems, members should be ductile, thus belonging to Class sections 1 or 2, according to the cross section classification defined in Eurocode 3 [12] and taken by NTC2008, as the same circular hollow sections should satisfy the requirement $d / t \leq 36$, where $\mathrm{d}$ and $\mathrm{t}$ are diameter and thickness of the circular hollow profile, respectively. Then the design of CBF-X diagonals is performed by considering only the contribution of braces in tension, assuming that at collapse braces in compression are already buckled and do not provide any bearing capability. With this assumption, the tensile braces are designed on the basis of the plastic resistance $N_{p l, R d}$, as it follows:

$$
N_{E d} / N_{p l, R d} \leq 1
$$

where $N_{E d}$ is the brace design axial force. Moreover, the normalized slenderness $(\bar{\lambda})$ of diagonals should be limited within the prefixed range $(1.3 \leq \bar{\lambda} \leq 2)$, where the upper limit has the aim to avoid excessive distortions due to buckling of braces in compression, which could cause damage to connections or to claddings, while the lower limit ensures the validity of the structural model with only active tensile braces as well as restricts the design internal forces in the columns, which are commensurated with respect to the plastic resistance of braces.

In order to prevent the untimely collapse of beams and columns, according to the hierarchy design criterion, the code requires to determine the overstrength factor $\Omega$ as it follows:

$$
\Omega=\Omega_{\min }=\left\{\frac{N_{p l, R d, i}}{N_{E d, i}}\right\}_{\text {min }}
$$

where $N_{E d, i}$ and $N_{p l, R d, i}$ are the brace design axial force and plastic resistance, respectively, at the ith level. The overstrength factor $\Omega$ indicates how much the axial force and then the seismic force can exceed the design value until the brace member reaches the complete plasticization. It is not the same for all the diagonals, it depending on the distribution of internal forces within the structure and on some sources of oversizing like for example the selection of structural members among the standard profiles or the need to provide lateral stiffness for deformability check requirements, further to the respect of the imposed limitation of slenderness. The latter condition is particularly strict at the upper stories, giving rise to $\Omega$ factor values increasing along the height of the structures. As a consequence, aiming at assuring a distribution in elevation as uniform as possible to promote the yielding of all the braces, the difference between the maximum and the minimum values should be limited to $25 \%$. Therefore, the following check is required:

$$
\frac{\Omega_{\max }}{\Omega_{\min }} \leq 1.25
$$

Moreover, considering the evidence that diagonals do not plasticize together at the same level of seismic forces, the $\Omega$ factor to be used for the application of the capacity design criterion is assumed as the minimum one, $\Omega_{\min }$, corresponding to the first not linear event, such as the plasticization of the first brace.
Once designed the braces and calculated the $\Omega$ factor, the capacity design criterion is applied for determining the design forces for beams and columns as it follows:

$$
N_{E d}=N_{E d G}+1.1 \gamma_{R d} \Omega_{\min } N_{E d E}
$$

where $N_{E d G}$ is the axial force corresponding to the nonseismic design loads, $N_{E d E}$ is the axial force corresponding to the seismic design loads; $\gamma_{R d}$ is the steel overstrength factor, that is the ratio between the average and the characteristic values of the yielding strength.

The behaviour factor $q$ for dissipative structures is assumed as equal to 4 for both low and high ductility classes. In the ideal condition in which the whole brace in tension is plasticized, the ductility and dissipation capability of the member would be much greater than how quantified by such a value of the q-factor. However it is not possible to be confident on such an ideal behaviour due to the uncertainties related to the behaviour of braces under cyclic actions due to seism. In fact braces undergo alternate states of tension and compression, therefore if the brace in compression buckles, the unstable deformation shape in bending is characterized by localized plastic deformation, thus the subsequent cycle in tension finds a degraded member, with limited ductile capabilities.

As far as the Damage Limit State is concerned, the code prescribes a limitation of the interstory drift equal to $1 \%$ when infill panels not rigidly connected to the main structure are adopted.

\section{THE CASE STUDY}

The study structures have typical configuration and geometrical dimensions. They belong to a regular building, 3,6 and 10 stories cases are examined, the interstorey height is $h=3.5 \mathrm{~m}$ (at the ground floor $h_{p t}=4 \mathrm{~m}$ ) and the bay span is $L=6 \mathrm{~m}$. The reference geometrical scheme is shown in Fig. (1). The structures are designed for high ductility class and they are assumed to be located in a high seismicity zone $\left(\mathrm{a}_{\mathrm{g}}=0.35 \mathrm{~g}\right)$ on a category B soil. For the sake of simplicity, the elastic spectrum is obtained according to the code OPCM 3431 [1] since seismic parameters are independent from the geographic position, unlike the current NTC2008. Dead loads are equal to $4.8 \mathrm{kN} / \mathrm{m}^{2}$ at every floor and $5.2 \mathrm{kN} / \mathrm{m}^{2}$ at the roof; live loads are assumed as equal to $2.0 \mathrm{kN} / \mathrm{m}^{2}$ at each floor. Each case study is designed through either the Linear Static (LS) or Linear Dynamic (LD) analysis, therefore in total 6 case studies are examined. The profiles used for the diagonal members are HE sections.

Seismic resistant systems
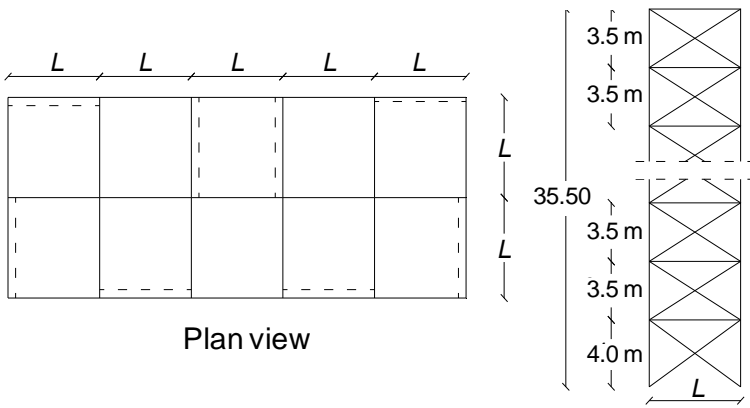

Fig. (1). Geometry of the investigated structures. 
The results of the design phases in terms of member profiles of the different investigated structures together with the total weight of each member type are provided in Tables from 1 to 3 .

\section{DESIGN ASSESSMENT OF CBF-X}

The NTC08 design criteria show a first critical issue in the ambiguity of the design procedure in the use of linear dynamic analysis results. In case of $\mathrm{CBF}-\mathrm{X}$, the code prescribes that at the ultimate limit state only the braces in tension resist the seismic forces, while the compressed braces are considered buckled and unable to provide strength. Nevertheless the vibration properties of the structure, i.e. periods and vibration modes, are strictly related to the linear behaviour and they should be determined considering the contribution of both braces in tension and in compression, therefore they cannot be calculated disregarding braces in compression. For this reason, for the structures examined the linear dynamic analysis is performed by considering the presence of both braces not only for evaluating the elastic vibration properties, but also for assessing seismic forces in the members. Then, in order to consider the model with only one active diagonal, the design of braces is carried out by assuming a value of the axial forces as the double of the one calculated by means of the structural model including both tensile and compressed diagonals (Fig. 2). Based on this, a possible improvement of the design criteria for $\mathrm{CB}-\mathrm{X}$ could be to clearly state this procedure within the code.

The design results show that the CBF-X structures designed with linear static (LS) analyses are generally subjected to seismic actions higher than those designed through linear dynamic (LD) analyses, as it is apparent from Table 4, where, with reference to the single CBF-X, $\mathrm{W}$ is the structural weight, $\mathrm{T}$ is the fundamental period of vibration, $\mathrm{F}_{\mathrm{h}}$ is the design base shear and $\Omega_{\min }$ is the design overstrength factor.
This difference is mainly related to the underestimation of the fundamental vibration period through the empirical formula provided by NTC2008 in case of linear static analyses. This issue is more evident for taller buildings. For instance, in the case of 10 -storey structures, the vibration period calculated by the code formula is $42 \%$ smaller than the one evaluated through dynamic analysis, with a consequent $61 \%$ increment of the total seismic force. This issue also influences the weight of the seismic resistant members. In particular, the structural weight of the structures designed through static analysis are up to $25 \%$ higher than those obtained by dynamic analysis. Based on this result, a possible improvement of the design criteria for $\mathrm{CB}-\mathrm{X}$ could be to define different simplified relationships for the preliminary determination of the fundamental period of vibration, depending on the number of floors.

Another critical issue observed in the design phase is the difficulty in selecting the bracing profiles. In particular, the lower bound of $\bar{\lambda}$ (equal to 1.3) strongly limits the HE profiles that can be used. In addition, the low seismic demand at upper storeys implies oversized bracings with corresponding very high $\Omega$ values. This especially occurs at the top storey, where the condition of uniformity of the $\Omega$ factor distribution along the structure height is hard to be satisfied (eq.3). Thus, for the 10-storey structures examined the top storey has not been considered in the check of the requirement concerning $\Omega$ values. Based on this results, a possible improvement of the design criteria for $\mathrm{CB}-\mathrm{X}$ could be to define more pertinent rules for the top storey. Some authors proposed a different approach based on the reduction of the bracing members section at the ends to obtain $\Omega=1[13,14]$

\section{NUMERICAL MODELLING ISSUES FOR CBF-X}

Structural analyses are performed by means of the FEM software SAP2000 v. 14.0.0 [15]. Members are modelled as beam elements with lumped plasticity, columns are continuous along the total height and both beam-to-column and

Table 1. Member profiles for 10 storeys CBF-X structures.

\begin{tabular}{|c|c|c|c|c|c|c|}
\hline \multirow{2}{*}{ Storey } & \multicolumn{3}{|c|}{ LS } & \multicolumn{3}{|c|}{ LD } \\
\hline & Diagonal & Column & Beam & Diagonal & Column & Beam \\
\hline 10 & HE $100 \mathrm{~A}$ & HE $180 \mathrm{~B}$ & IPE 220 & HE $100 \mathrm{~A}$ & HE $180 \mathrm{~B}$ & IPE 220 \\
\hline 9 & HE $100 \mathrm{~A}$ & HE $180 \mathrm{~B}$ & IPE 220 & HE $100 \mathrm{~A}$ & HE $180 \mathrm{~B}$ & IPE 220 \\
\hline 8 & HE $120 \mathrm{~A}$ & HE $260 \mathrm{~B}$ & IPE 270 & HE $100 \mathrm{~A}$ & HE $240 \mathrm{~B}$ & IPE 220 \\
\hline 7 & HE 140 A & HE $260 \mathrm{~B}$ & IPE 270 & HE $120 \mathrm{~A}$ & HE $240 \mathrm{~B}$ & IPE 240 \\
\hline 6 & HE 140 B & HE $360 \mathrm{~B}$ & IPE 300 & HE $120 \mathrm{~A}$ & HE $280 \mathrm{~B}$ & IPE 240 \\
\hline 5 & HE 140 B & HE $360 \mathrm{~B}$ & IPE 300 & HE $120 \mathrm{~B}$ & HE $280 \mathrm{~B}$ & IPE 270 \\
\hline 4 & HE 140 B & HE $360 \mathrm{M}$ & IPE 330 & HE $120 \mathrm{~B}$ & HE $280 \mathrm{M}$ & IPE 270 \\
\hline 3 & HE $100 \mathrm{M}$ & HE $360 \mathrm{M}$ & IPE 330 & HE $120 \mathrm{~B}$ & HE $280 \mathrm{M}$ & IPE 270 \\
\hline 2 & HE $100 \mathrm{M}$ & HE $500 \mathrm{M}$ & IPE 330 & HE 140 B & HE $300 \mathrm{M}$ & IPE 300 \\
\hline 1 & HE $100 \mathrm{M}$ & HE $500 \mathrm{M}$ & IPE 330 & HE $140 \mathrm{~B}$ & HE $300 \mathrm{M}$ & IPE 300 \\
\hline Member weight $[\mathrm{kN}]$ & 43 & 115 & 28 & 33 & 96 & 20 \\
\hline
\end{tabular}


Table 2. Member profiles for 6 storeys CBF-X structures.

\begin{tabular}{|c|c|c|c|c|c|c|}
\hline Storey & \multicolumn{3}{|c|}{ LS } & \multicolumn{3}{|c|}{ LD } \\
\hline 5 & HE $120 \mathrm{~B}$ & HE $200 \mathrm{~B}$ & IPE 270 & HE $140 \mathrm{~A}$ & HE $200 \mathrm{~B}$ & IPE 240 \\
\hline 4 & HE 140 B & HE $300 \mathrm{~B}$ & IPE 330 & HE 140 B & HE $280 \mathrm{~B}$ & IPE 300 \\
\hline 2 & HE $100 \mathrm{M}$ & HE $300 \mathrm{M}$ & IPE 360 & HE $100 \mathrm{M}$ & HE $280 \mathrm{M}$ & IPE 330 \\
\hline 1 & HE $120 \mathrm{M}$ & HE $300 \mathrm{M}$ & IPE 360 & HE $100 \mathrm{M}$ & HE $280 \mathrm{M}$ & IPE 330 \\
\hline Member weight $[\mathrm{kN}]$ & 30 & 60 & 20 & 27 & 52 & 16 \\
\hline
\end{tabular}

Table 3. Member profiles for 3 storeys CBF-X structures.

\begin{tabular}{|c|c|c|c|}
\hline \multirow{2}{*}{ Storey } & \multicolumn{2}{|c|}{ LS-LD } \\
\cline { 2 - 4 } & Diagonal & Column & Beam \\
\hline \hline 3 & HE $100 \mathrm{~A}$ & HE $260 \mathrm{~B}$ & IPE 220 \\
\hline 2 & HE $140 \mathrm{~A}$ & HE $260 \mathrm{~B}$ & IPE 300 \\
\hline 1 & HE $140 \mathrm{~B}$ & HE $260 \mathrm{~B}$ & 20 \\
\hline
\end{tabular}

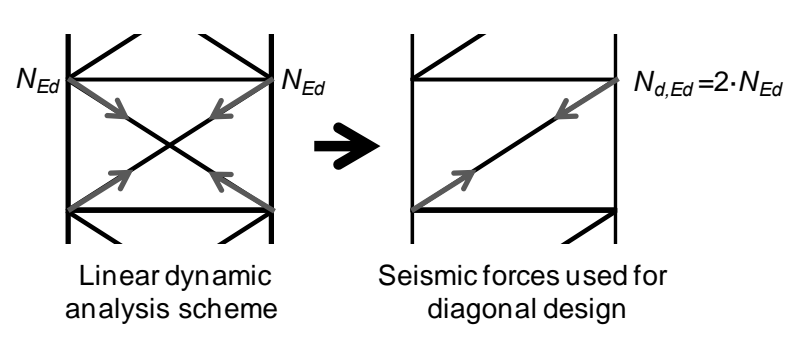

Fig. (2). Structural scheme assumed for linear dynamic analysis.

Table 4. Design results for CBF-X structures.

\begin{tabular}{|c|c|c|c|c|c|}
\hline \multirow{2}{*}{ LS } & 3 & 37 & $0.30^{*}$ & 348 & 2.52 \\
\hline & 10 & 186 & $0.73^{*}$ & 781 & 1.44 \\
\hline LD & 10 & 149 & 1.25 & 486 & 1.75 \\
\hline
\end{tabular}

* $T=C_{1} H^{3 / 4}$ with $C_{1}=0.05, H=$ total height of the structure

brace-to-beam connections are hinged. Plastic hinges of beams and columns are modelled by considering the classic elastic-perfectly plastic constitutive law [16].
For bracing members, the definition of the behavioural model under seismic actions is still an open issue, due to the complexity of the actual behaviour $[17,18]$. The force- 
displacement model assumed in the study is shown in (Fig. 3), where every significant limit state point is evidenced.

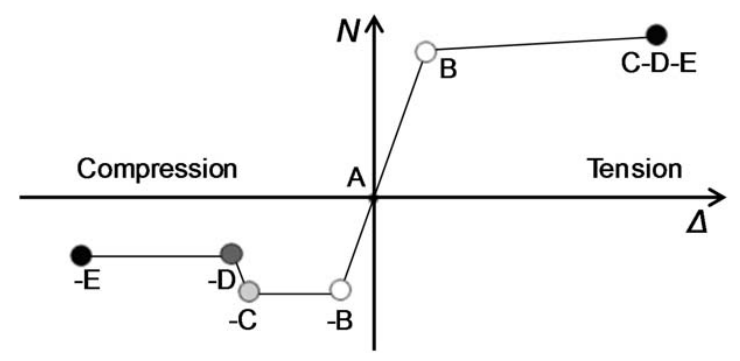

Fig. (3). The bracing member behaviour: assumed model.

It is a simplification of the mathematical model proposed by Georgescu [19], which is depicted in Fig. (4). The brace ductility is limited according to the simplified approach proposed by Tremblay [20]. In this way, it is possible to take into account, although with approximation, the actual behaviour of braces in compression, consisting in the buckling and then post-buckling phases, where a loss of strength and stiffness results in a reduction of the brace dissipative capacity.

In particular, the Georgescu model is based on the following main assumptions (Fig. 4): under horizontal forces one brace is in compression, the other in tension, the behaviour is initially linear-elastic with the same behaviour in tension and in compression (branch OA); when the compression force attains the buckling resistance, the compressed brace assumes a non-linear behaviour, the force cannot further increase, while lateral displacements grows till a given level at a constant force (branch $\mathrm{AB}$ ); for larger displacements, the resistance decreases determining the post-critical condition (branch BC).

In order to provide a ductility limit for braces, reference is made to the wide experimental campaign performed by Tremblay [18], including bracing systems with different cross-sections, namely rectangular and circular hollow sections (RHS [ $4 \times 2 \times 0.125-152 \times 152 \times 9.5] \mathrm{mm}$, (Pipe [4.0x0.226$4.5 \times 0.237] \mathrm{mm})$, double $\mathrm{T}$ profiles $(\mathrm{W}[6 \times 15.5-8 \times 21] \mathrm{mm})$, C-profiles side by side $([50 \times 50 \times 6 \times 6] \mathrm{mm})$. Tremblay proposed a simplified approach in which the total available duc- tility $\mu_{F}$ is given as a function of the normalised slenderness $\bar{\lambda}: \mu_{F}=a+b \bar{\lambda}$, where $a$ and $b$ are 2.4 and 8.4, respectively. The ductility $\mu_{F}$ is considered as the sum of the ductility in compression and in tension.

\section{BEHAVIOUR FACTOR EVALUATION}

The behaviour factor $q$ is a coefficient which allows to perform an elastic seismic analysis of the structure, taking into account the inelastic behaviour capabilities. It is a measure of the structural ductility and depends on the type of seismic resistant system. The $\mathrm{q}$ factor is used as a reduction coefficient of the elastic spectrum, which characterizes the elastic response at the earthquake site, thus obtaining a design inelastic spectrum. In this way it is possible to perform a seismic structural analysis in elastic field, with reduced seismic actions as respect to those corresponding to the elastic response under the site earthquake, accepting at the ultimate limit state a degree of permanent damage due to inelastic deformation associated to seismic input energy dissipation. Therefore, the q factor represents the ratio between the resistance that the structure has to possess to remain in elastic range, $F_{e}$, and the design resistance under earthquake, $F_{h}$. The latter is generally slightly lower than the actual structure resistance corresponding to the occurrence of the first nonlinear event in the structural system, $F_{1}$, because of the intrinsic design overstrength (Fig. 5).

With this premises, also the definition of the behaviour factor $\mathrm{q}$ is an open issue.

The q factor assumed in the study is determined, coherently with the previous definitions, according to the following equation [21]:

$$
q=\frac{F_{e}}{F_{h}}=q_{\Omega} \cdot q_{\mu}=\left(\frac{F_{1}}{F_{h}} \cdot \frac{F_{u}}{F_{1}}\right) \cdot \frac{d_{u}}{d_{y}}=\frac{F_{u}}{F_{h}} \cdot \frac{d_{u}}{d_{y}}
$$

where $q_{\Omega}$ and $q_{\mu}$ are the behaviour factor contributions related to overstrength and ductility, respectively; $F_{1}$ is the base shear at the first non-linear event, $F_{h}$ is the design base shear, $F_{u}$ is the maximum base shear value on the pushover curve, $d_{y}$ is the displacement corresponding to the conventional elastic limit and $\mathrm{d}_{\mathrm{u}}$ is the ultimate displacement. The

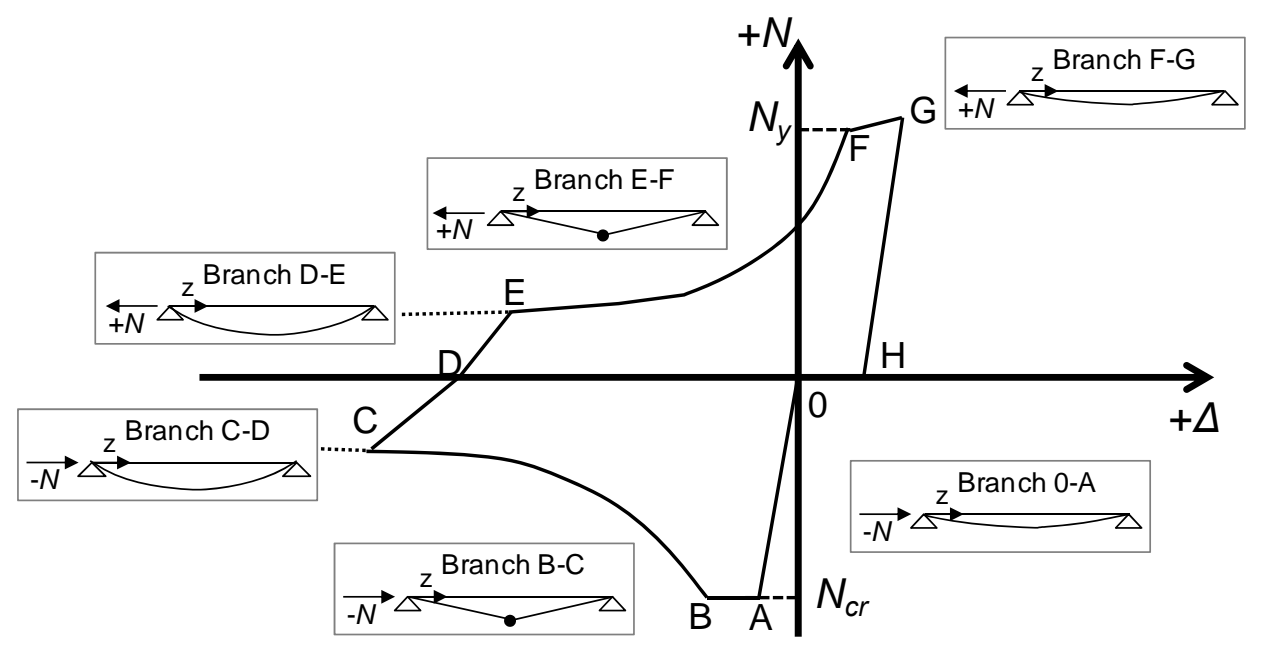

Fig. (4). The bracing member behaviour: Georgescu model [19]. 
$q_{\Omega}$ factor takes into account the structure overstrength, through the ratio $F_{1} / F_{h}$, and the plastic redistribution capacity through the ratio $F_{u} / F_{1}$. In particular the $q_{\mu}$ factor represents the structure ductility, it being given by the ratio $d_{u} / d_{y}$ (for $T^{*}>T_{C}$, where $T^{*}$ is the fundamental period of the equivalent SDOF system and $T_{C}$ is the limit period between the constant acceleration region and constant velocity region of the design spectrum).

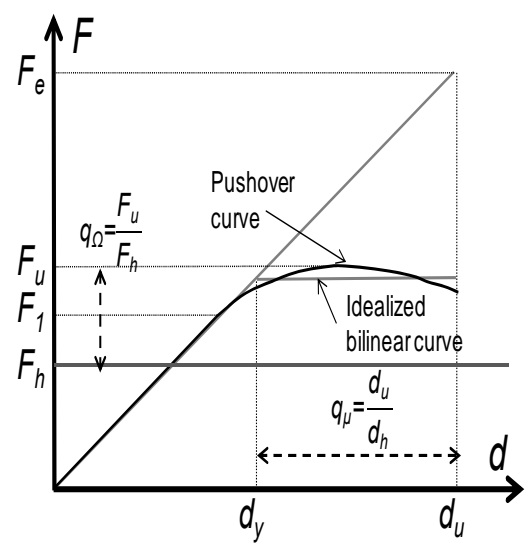

Fig. (5). Evaluation of the behaviour factor.

The application of equation (5) for the definition of the $q$ factor requires another assumption to be made, it being related to the selection of the ultimate condition, which $d_{u}$ corresponds to.

In this work, the behaviour factor is calculated according to two different definitions for the ultimate displacement $d_{u}$. In the first case the behaviour factor, namely $q$, corresponds to $d_{u}$ as the lowest displacement among those corresponding either to the development of a collapse mechanism, or the achievement of the diagonal maximum local ductility of the brace, or the $15 \%$ strength loss with respect to the peak force on the pushover curve. In the second case the behaviour factor, namely $q_{2 \%}$, corresponds to $d_{u}$ at the achievement of the interstorey drift equal to $2 \%$, as provided by FEMA 356 for braced steel structures at Collapse Prevention limit state [22].

\section{SEISMIC PERFORMANCE EVALUATION}

The seismic performance of the structures is evaluated in terms of collapse modes and behaviour factors, aiming at the evaluation of the accuracy of design assumptions.

In Figs. (6) and (7) the failure modes (Fig. 6) and pushover curves (Fig. 7) for the investigated CBF-X structures are depicted. In Fig. (6) the points reported correspond to the limit states defined in Fig. (3).

The failure modes exhibited by the structures examined always differ from the global mechanism. In particular, the $2 \%$ inter-storey drift limit is always attained before the other previously defined ultimate conditions and the crisis is located in a single storey, where the complete yielding of the braces in tension occurs. As a consequence, plastic hinges at the columns ends develop with the loss of load-bearing capacity of the entire structures (Fig. 6 and 7). Nevertheless, for the investigated cases, the collapse occurs after the yielding of a large number of braces, which is more than $60 \%$ of the total ones. This means that the applied design criteria allow for a fair dissipative behaviour of the structures investigated.

Furthermore, acceptable values of ductility are ensured, $q_{\mu}$ ranging from 2.1 to 2.9 when only some braces are yielded and from 3.0 to 4.0 when all braces are yielded (Table 5).

Table 5 shows the values of the behaviour factors $q$ and $q_{2 \%}$, as defined in Section 6. As far as the behaviour factor $\mathrm{q}$ is concerned, the obtained values are always greater than the standard one $(q=4)$. In particular, they range from 4.5 to 11.7 and show an increasing trend with the decreasing of the storeys number. The high values of the behaviour factor, for 3 and 6 storeys structures, are due to the oversizing of the

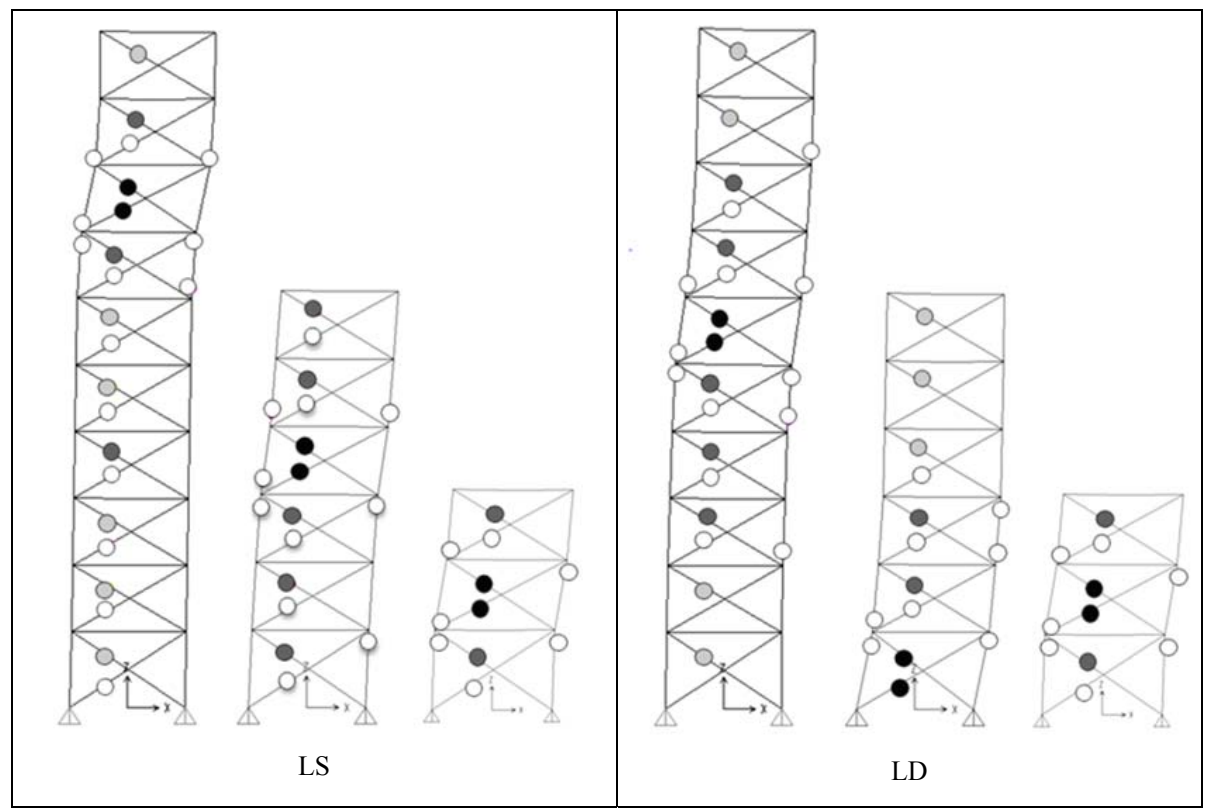

Fig. (6). Failure modes for investigated CBF-X structures. 
structural members, as confirmed by the high $\Omega$-values detected. These behaviour factors have a very high overstrength contribution $\left(q_{\Omega}\right)$, which attains values up to 3.88 .
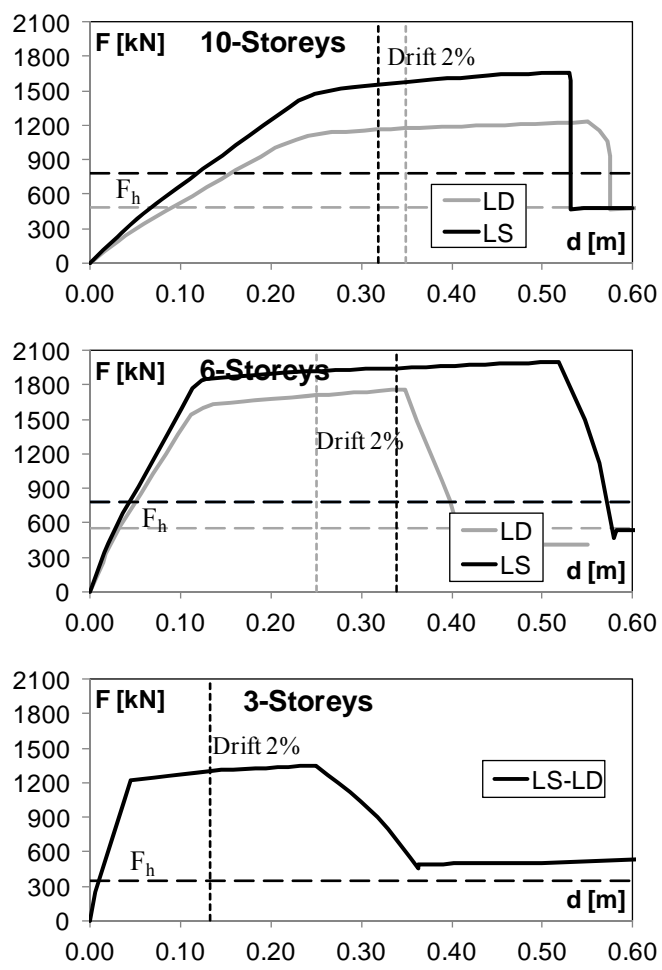

Fig. (7). Pushover curves for investigated CBF-X structures.

On the other hand, the obtained values of the behaviour factor $q_{2} \%$ are quite lower than those of q factor with differences of about $70 \%$ for 10 -storeys structures and $40 \%$ for the other structures. In the case of 10 -storeys structures, $q_{2} \%$ ranges from 2.7 to 3.2 and is lower than the standard one, while for the other structures $q_{2} \%$ is greater, it ranging from 6.9 to 8.5 . The difference between $q$ and $q_{2} \%$ factor depends substantially by the lower ductility contribution in case where $2 \%$ drift attainment is assumed as ultimate condition $\left(q_{\mu}=1.3 \div 2.9\right)$, while very little differences are observed in terms of $\Omega$-values.
This evidence demands a focus on the identification of the ultimate conditions to be referred to, aiming at the definition of the $\mathrm{q}$ factor, which should be also attributed according to the number of stories. Also the design objective at the ultimate limit state could be calibrated, considering that also partial collapse mechanism could correspond to suitable performances in terms of ductility and dissipation capabilities.

\section{CONCLUSION}

The Italian technical code for constructions (NTC 2008), inspired by Eurocode 8, provides a number of design criteria for steel concentric bracing structures in seismic zone. Nevertheless, their application appears difficult and, sometimes, not effective in achieving the prefixed design objectives. In fact, the simplified computational models proposed by the code do not allow to capture some key aspects of the behaviour of the investigated systems and, generally, to achieve the desired structural performance. In particular the following aspects requires to be improved:

Design procedure: specification of the procedure for the application of linear dynamic analysis coherently with the model of only tensile brace active; definition of different simplified relationships for the preliminary determination of the fundamental period of vibration, depending on the number of floors; definition of more pertinent rules for the top storey, in terms of slenderness of braces, in order to reduce the overstrength and then the $\Omega$ factor.

Structural model: definition of the force-displacement behavioural model for bracing members in tension and compression, comprehensive of all the significant aspects of the actual behaviour.

Behaviour factor: identification of the ultimate conditions for defining the q factor; attribution of the $\mathrm{q}$ factor to CBF-X according to the number of stories; calibration of the design objective at the ultimate limit state, considering that also partial collapse mechanism could correspond to suitable performances in terms of ductility and dissipation capabilities.

Therefore, results acquired in the current paper can be usefully adopted to plan an extensive campaign of experimental and numerical investigations aiming at both optimizing the calculation models and providing simplification to the design procedures.

Table 5. Behaviour factors of investigated CBF-X structures.

\begin{tabular}{|c|c|c|c|c|c|c|c|c|}
\hline \multirow{2}{*}{ Analysis Method } & \multirow{2}{*}{ N. storeys } & \multicolumn{3}{|c|}{$q$} & \multicolumn{3}{|c|}{$q_{2 \%}$} & \multirow{2}{*}{$\begin{array}{c}\% \text { yielded } \\
\text { bracing }\end{array}$} \\
\hline & & $q_{\mu}$ & $q_{\Omega}$ & $\boldsymbol{q}_{\mu} \times \boldsymbol{q}_{\Omega}$ & $\boldsymbol{q}_{\mu}$ & $q_{\Omega}$ & $\boldsymbol{q}_{\mu} \times \boldsymbol{q}_{\Omega}$ & \\
\hline \multirow{3}{*}{ LS } & 3 & 3.01 & 3.88 & 11.7 & 2.26 & 3.75 & 8.49 & 100 \\
\hline & 6 & 3.98 & 2.91 & 11.6 & 2.91 & 2.83 & 8.24 & 100 \\
\hline & 10 & 2.10 & 2.12 & 4.46 & 1.34 & 1.99 & 2.66 & 90 \\
\hline \multirow{3}{*}{ LD } & 3 & 3.01 & 3.88 & 11.7 & 2.26 & 3.75 & 8.49 & 100 \\
\hline & 6 & 2.88 & 3.21 & 9.25 & 2.20 & 3.12 & 6.88 & 67 \\
\hline & 10 & 2.15 & 2.52 & 5.42 & 1.32 & 2.42 & 3.19 & 60 \\
\hline
\end{tabular}




\section{CONFLICT OF INTEREST}

The authors confirm that this article content has no conflict of interest.

\section{ACKNOWLEDGEMENTS}

The authors gratefully acknowledge the Department of Civil Protection for the research funding within the RELUISDPC 2010-2013 and 2014 projects.

\section{REFERENCES}

[1] Decree of the Minister Council Presidency 03/05/2005 n. 3431 (OPCM) (2005), Further modifications and integrations to the Decree of the Minister Council Presidency 20/03/2003 n. 3274 (in Italian)

[2] CEN, EN 1998-1:2005. Eurocode 8: Design of structures for earthquake resistance - Part 1: General rules, seismic actions and rules for buildings, European Committee for Standardization, EN 19981, Bruxelles, 2005.

[3] F.M. Mazzolani, and G. Della Corte, "Steel structures in seismic zone - M.D. 2008" (in Italian), Il Sole 24 Ore (Ed.), 2008.

[4] Ministerial Decree 14/01/2008 (M.D.), D.M. New technical codes for constructions (in Italian), 2008.

[5] Ministerial Circular 02/02/2009 n. 617 (M.C.), Instructions for application of the "New technical codes for constructions" (in Italian), 2009

[6] T. De Lucia, A. Formisano, L. Fiorino, B. Faggiano, and F.M. Mazzolani "Optimization of design criteria for seismic steel structures with chevron concentric bracing frames" (in Italian). Proc. of the XV Anidis Congress "L'Ingegneria sismica in Italia", Padova, 30 June -4 July. Braga, F. \& Modena, C. (Eds.). Padova University Press Publisher. ISBN 978-88-97385-59-2. Paper n. F7 on CDRom, 2013.

[7] V. Macillo, C. Castaldo, L. Fiorino, A. Formisano, B. Faggiano, and F.M. Mazzolani, "Critical review of the NTC2008 design criteria for steel concentric bracing frames". Proc. of the International Workshop High Strength Steel in Seismic Resistant Structures (HSS_SERF), Naples, Italy, 28-29 June 2013.

[8] V. Macillo, C. Castaldo, L. Fiorino, A. Formisano, B. Faggiano, and F. M. Mazzolani (2014). Evaluation of the italian seismic code for the design of concentrically $x$-braced steel structures. In 7th European Conference on Steel and Composite Structures (EUROSTEEL 2014), Napoli, Italia, 10-12 Settembre, Landolfo \& Mazzolani (Eds.), Published by ECCS European Convention for Constructional Steelwork. ISBN 978-92-9147-121-8, paper n.05693.

[9] C. Castaldo, V. Macillo, A. Formisano, L. Fiorino, B. Faggiano, and F. M. Mazzolani (2014). "Evaluation of the italian seismic code for the design of concentrically V-braced steel structures". In 7th European Conference on Steel and Composite Structures (EUROSTEEL 2014), Napoli, Italia, 10-12 Settembre, Landolfo \& Mazzolani (Eds.), Published by ECCS European Convention for Constructional Steelwork. ISBN 978-92-9147-121-8, paper n.06677.

[10] A. Longo, R. Montuori, and V. Piluso. "Failure mode control of Xbraced frames under seismic actions", Journal of Earthquake Engineering, vol. 12, no. 5, pp. 728-59, 2008.

[11] A. Longo, R. Montuori, and V. Piluso, "Plastic design of seismic resistant V-braced frames", Journal of Earthquake Engineering, vol. 12, no. 8, pp. 1246-66, 2008.

[12] CEN, EN 1998-1:2005. Eurocode 3: Design of steel structures Part 1-1: General rules and rules for buildings, European Committee for Standardization, EN 1993-1, Bruxelles, 2005.

[13] M. T. Giugliano, A. Longo, R. Montuori, and V. Piluso, " Plastic design of CB-frames with reduced section solution for bracing members", Journal of Constructional Steel Research, vol. 66, no. 5, pp. 611-21, 2010.

[14] M. T. Giugliano, A. Longo, R. Montuori, and V. Piluso, "Seismic reliability of traditional and innovative concentrically braced frames", Earthquake Engineering and Structural Dynamics, vol. 40, no. 13, pp. 1455-1474, 2011.

[15] CSI, Computer program SAP2000 - Berkeley University - California - USA - version 14.0.0, June, 2008.

[16] F.M. Mazzolani, and V. Piluso, "Theory and design of seismic resistant steel frames", Taylor and Francis CRC, 1996.

[17] M. D’Aniello, G. La Manna Ambrosino, F. Portioli, and R. Landolfo, "Modelling aspects of the seismic response of steel concentric braced frames", Steel and Composite Structures, An International Journal, vol. 15, no. 5, pp. 539-66, 2013.

[18] M. D’Aniello, G. La Manna Ambrosino, F. Portioli, and R. Landolfo, "The influence of out-of-straightness imperfection in Physical-Theory models of bracing members on seismic performance assessment of concentric braced structures", The Structural Design of Tall and Special Buildings, 2014 (published online 20 April 2014). DOI: $10.1002 /$ tal.1160.

[19] D. Georgescu, "Recent developments in theoretical and experimental results on steel structures. Seismic resistant braced frames", Costruzioni Metalliche, vol. 11, pp. 39-50, 1996.

[20] R. Tremblay, "Inelastic seismic response of steel bracing members", Journal of Constructional Steel Research, vol. 58, pp. 665701, 2002.

[21] C.M. Uang, "Establishing R (or Rw) and Cd Factors for Building Seismic Provisions", Journal of structural Engineering, vol. 117, pp. 19-28, 1991.

[22] FEMA 356, Prestandard and Commentary for the Seismic Rehabilitation of Buildings, American Society of Civil Engineers, Washington, DC, 2000.

(C) Faggiano et al.; Licensee Bentham Open.

This is an open access article licensed under the terms of the Creative Commons Attribution Non-Commercial License (http://creativecommons.org/licenses/by-nc/3.0/) which permits unrestricted, non-commercial use, distribution and reproduction in any medium, provided the work is properly cited. 